How much does this really amount to in practice? And there is seldom any after operation in uncomplicated cases.

3. Fewer instruments introduced into the eye.

Apparently Dr. Johnson Taylor considers that the risk of dealing with a prolapse at a second operation is less serious than passing iridectomy forceps into the eye at the first operation.

4. Much less bleeding.

How often do we meet with bleeding when the iris is cut, except in diabetic cases and those with very degenerated vessels ?

5. Much less risk of prolapse of the vitreous.

Operators who are gentle.in their manipulation seldom get prolapse of the vitreous, except in complicated cataracts where the tendency is suspected beforehand.

6. Practically no risk of capsule being drawn up into the wound, etc.

This is the only real advantage of a simple extraction, and is well known to all advocates of the combined method, and has been carefully weighed against the one real disadvantage, viz.:- prolapse.

7. When needling the capsule . . . causing increased tension.

How often has Dr. Johnson Taylor seen rise of tension after needling? It is undoubtedly rare considering the number of needlings that are undertaken.

And what. is Dr. Johnson Taylor's definition of a "good" operator? To take an example from a sport which I know best. A mountaineer is recognized as "good" when he is a safe man to go with; who takes all the risks, reduces them to a minimum, and never forgets for a moment that the lives of his companions on the rope are largely in his hands. He may not be a brilliant cragsman, nor a man who can glissade gracefully and keep his balance down a snow slope of 1000 feet; but he is a "good" mountaineer for all that. The same principle may apply to a surgeon and an operator.

\title{
Yours, \&c.,
}

MalColm L. HepbuRn.

HARLEY STREET,

Cavendish Square, W.1.

February 23, 1918.

\section{BOOK NOTICES}

Eye, Ear, Nose and Throat. A manual for students and practitioners. By Dr. H. C. BALlenger and Dr. A. G. WIPPERN. New second edition. Pp. 524, with I80 engravings and eight coloured plates. Lea \& Febiger, Philadelphia and New York, rigi7. Price $3 \frac{1}{2}$ dollars.

The first 164 pages of this work are written by Wippern and deal with ocular diseases. This space, all too brief, is : further 
partly occupied by a number of illustrations reproduced from wellknown text-books. Ophthalmology is too large a subject for adequate treatment as part of a text-book that also deals with throat, ear, and nose. That the book has reached a second edition shows that there must be a demand for a condensed account of these specialities in a small compass, and Wippern has made the most of the space at his disposal. We notice that when dealing with the treatment of errors of refraction, he states, "the use of a cycloplegic will, it is believed, give the best results under forty years of age, and accordingly atropin should be used when the patient can spare the time."' It is true that he qualifies this statement by saying that a cycloplegic is not necessary in the examination of presbyopes, and may be dangerous in very rare cases from increase of intra-ocular pressure. As the book is chiefly likely to be of use to senior students, we do not think the idea of the safety of the use of atropin up to forty years of age is a sound one to suggest.

E. E. H.

Eye, Ear and Throat Hospital for Shropshire and North Wales, 1818-1918. Shrewsbury: Wilding \& Son, Ltd., Castle Street.

In commemoration of the centenary of the Eye, Ear and Throat Hospital for Shropshire and North Wales at Shrewsbury, a pamphlet has been issued giving the history of the institution since its foundation in 1818. Although there is some doubt in whose mind the idea of the hospital originated, there is none that Dr. G. F. D. Evans was the first surgeon to the dispensary, as it then was. The work was carried on in one room in the latter's house. At that time the sole provision for those requiring inpatient treatment was by lodgings in the town, with some assistance in suitable cases from the funds of the institution. In 1832, after thirteen years of strenuous work on behalf of the institution, Dr. Evans retired, and was succeeded by Mr. Edwin Foulkes, who held the post of honorary surgeon until his death in 1861. His successor was Dr. Edwin Andrew, who was responsible for many improvements, especially as regards the provision of accommodation for in-patients. The post of consulting surgeon was offered to and accepted by Mr. Soelberg Wells, professor of ophthalmology at King's College, London, who was succeeded by Mr. Brudenell Carter. A new hospital, situated on the present site overlooking the Severn, was opened in 1881. One old lady, who had been an inmate of the first hospital, where there was a daily modicum of beer, expressed her feelings on being transferred to the new building, where that luxury was not allowed, in the following words: "This new hospital may be very beautiful, no doubt, but 
there's too much air and too little beer, so I prefer the old place." Andrew, who died in 1887, was followed by William Charnley, once surgeon to the Central London Ophthalmic Hospital, who suggested the provision of a private ward for paying patients in the hospital. After Charnley's death in 1900, the present surgeon, Mr. C. G. Russ Wood, took office. In order to give readers some idea of the importance of the work carried on at Shrewsbury, it may be stated that in the year 1917 some 5,000 new patients were admitted, while over 1,000 operations were performed. S. S.

The American Encyclopedia and Dictionary of Ophthalmology. Edited by CASEY A. Wood, M.D., C.M., D.C.L., assisted by a large staff of collaborators. Volume XI.-Muscles, Ocular, to Ophthalmology, History of. Chicago : Cleveland Press, 1917.

It is possible that this, the eleventh volume of the American Encyclopedia, may be considered by a number of readers to be the finest yet published. It contains two chief articles, namely, that on Ocular Muscles (commenced in the previous volume) and History of Ophthalmology. Other articles of importance are Oblique Astigmatism and Neurology of the Eye, but the two firstnamed are those which give to the volume its character.

The Ocular Muscles caption (as the Americans prefer to call such divisions of the volume) is divided into two parts by the fact of being by two authors, each writing his own part. The physiology and pathology is by Dr. G. C. Savage, and the operative treatment by Dr. Edward Jackson. America has long been in the forefront on this subject which, in these pages, receives the fullest possible treatment. Whether one wishes information on the anatomical, the physiological or the therapeutic sides of it, one will not go in vain to this treatise. The illustrations are excellent and are very numerous. Nearly 70 illustrations are concerned with operations, the majority of these illustrating the steps of the best known procedures. - Needless to say, "partial" tenotomy in its various forms receives much attention.

The reviewer has, on a previous occasion, expressed his wonder at the work of Dr. T. H. Shastid, who writes most, if not all, the biographies in this Encyclopedia. But what is the biography of a single individual to a man who can also write four hundred pages or so on the History of Ophthalmology, incidentally including the whole book of Aetius of Amida, and Galen's Anatomy and Physiology of the Eye translated into English by Shastid himself ? To any ordinary reviewer, not himself fairly acquainted with the history of medicine, criticism or full appreciation is impossible.

ERNEST THOMSON. 